\title{
The Inhibitory Effect of Cyclodextrin on Oxygen Bioavailability Is a Key Factor for the Metabolic Flux Redistribution Towards Steroid Alcohols in Phytosterol Resting Cells Bioconversion
}

\section{Xuedong Wang ( $\sim$ xdwang@ecust.edu.cn )}

State Key Laboratory of Bioreactor Engineering, New World Institute of Biotechnology, East China

University of Science and Technology https://orcid.org/0000-0001-7618-5847

\section{Kuan Chen}

East China of University of Science and Technology

\section{Dandan Cao}

East-China Institute of Technology: East China University of Science and Technology

\section{Dongzhi Wei}

East China University of Science and Technology

\section{Original Article}

Keywords: hydroxypropyl- $\beta$-cyclodextrin, Mycobacterium, oxygen bioavailability, steroid alcohol, redox balance

Posted Date: February 16th, 2021

DOI: https://doi.org/10.21203/rs.3.rs-196986/v1

License: (c) (i) This work is licensed under a Creative Commons Attribution 4.0 International License.

Read Full License

Version of Record: A version of this preprint was published at Applied Biochemistry and Biotechnology on March 13th, 2021. See the published version at https://doi.org/10.1007/s12010-021-03540-w. 


\section{Abstract}

In the present work, we tried to identify the mechanism why by which the steroid alcohols accumulated when hydroxypropyl- $\beta$-cyclodextrin (HP- $\beta$-CD) was present to enhance the sterol conversion rate. Compared with the bioconversion system without HP- $\beta-C D$, the reaction rate was greatly improved in presence of HP- $\beta-C D$, but the steroid alcohols largely accumulated concurrently. The concentration of steroid alcohols increased with the enhanced reaction rate and the higher intracellular NADH/NAD level was detected. Mycobacterium neoaurum mutants with higher KshA activity (3-ketosteroid 9a-hydrolase, a monooxygenase hydroxylating the nucleus at $\mathrm{C}-9$ at the expense of $\mathrm{NAD}(\mathrm{P}) \mathrm{H}$ consumption) reduced the steroid alcohols production and in the meantime, the NADH/NAD ${ }^{+}$level was decreased consequently. Further research found that oxygen availability was seriously inhibited by the cyclodextrin in a reaction system. These results indicated that NADH formed in the bioconversion was not properly regenerated via the respiratory chain because of the poor oxygen bioavailability. The inhibitory effect of cyclodextrin on oxygen bioavailability is a key factor for the metabolic flux redistribution towards steroid alcohols in phytosterol resting cells bioconversion.

\section{Introduction}

In recent decades, the cleavage of sterol side chain by microbes (bacteria and fungi) was widely investigated to produce steroids, such as 4-androstene-3,17-dione (AD) and 1,4-androstadiene-3,17-dione (ADD) [1]. The steroid intermediates production is carried out by microbials through the cleavage of the side chain of steroids at C-17, which is similar to the $\beta$-oxidation process of fatty acids [2]. Key genes involved in sterol degradation were identified with the help of genome sequencing and sequence analysis $[3,4]$. Furtherly, genome sequence analysis and gene engineering promoted the development of engineered strains for steroids production through bioconversion process [5-7].

One of the reasons that phytosterol bioconversion proceeds slowly was due to the extremely low solubility of sterols in the aqueous phase [2]. To tackle this problem, measures have been used to enhance the bioavailability of substrate, including the use of surfactants, ionic liquids, oil-water emulsification, cyclodextrin [8-10]. Among them, CD, especially HP- $\beta-C D$, was reported to be an excellent performance in the enhancement of phytosterols conversion rate mainly by forming the sterolcyclodextrin inclusion complex [10]. As reported, CDs have multiple functions on the sterol bioconversion, including the potential inhibition of steroid core degradation, the increase of cell wall permeability for both steroids and nutrients to promote the sterol bioconversion or the inhibition of the expression of some genes related to sterol degradation [11-13].

In our previous work, the efficient bioconversion of phytosterols to steroids using engineered Mycobacterium neoaurum was achieved through a HP- $\beta$-CD-resting cells reaction system [14]. High sterol concentrations and reaction rates showed that the bioprocess of microbial side-chain cleavage of phytosterols for steroids production was useful even in industry. However, we also found by quantitative analysis of individual metabolites, that the steroid C22-alcohols were accumulated during the 
bioconversion process. This result was in agreement with the researches of Donova et al [1] but the formation mechanisms are still unknown. During the sterol degradation, NADH $\left(\mathrm{FADH}_{2}\right)$ and ATP are formed to supply the reducing power and energy for cells growth and metabolism [2]. Many approaches showed that the intracellular redox level in sterol biotransformation played an important role in promoting steroid biotransformation and regulating the metabolic distribution $[15,16]$.

In this work, the steroidal intermediates production was carried out in a HP- $\beta$-CD-resting cells reaction system. The steroid alcohols accumulation in the bioprocess under the condition of different reaction rate were investigated. The possible factors, such as NADH/NAD ${ }^{+}$and dissolved oxygen level, affecting metabolic redistribution leading to the formation of steroid alcohols were discussed. The objective of this research is to clarify the mechanism of steroid alcohols accumulation in the sterol bioconversion.

\section{Materials And Methods}

\section{Strain and media}

The strain of M. neoaurum ATCC 25795 and its mutants used in this study are shown in Table 1. Engineered strains were constructed according to the procedure of reference as previously stated [17].

Table 1 Strains used in this study

\begin{tabular}{|lll|}
\hline M. neoaurum & Description & References \\
\hline NwIB-R10 & NwIB-R10- $\Delta k s h A$, AD producer. & {$[17]$} \\
\hline NwIB-R10-kshA & NwIB-R10- $\Delta k s h A:: k s h A$ & This study \\
NwIB-yV & NwIB-yV-pMV261-kshA; 9-OHAD producer. & {$[17]$} \\
\hline
\end{tabular}

Preculture medium consisted (per liter) of $0.5 \mathrm{~g} \mathrm{~K}_{2} \mathrm{HPO}_{4}, 0.5 \mathrm{~g} \mathrm{MgSO}_{4}, 2.68 \mathrm{~g} \mathrm{NH}_{4} \mathrm{Cl}, 2.0 \mathrm{~g}$ citric acid, 0.05 $\mathrm{g}$ ammonium ferric citrate, $20.0 \mathrm{~g}$ glycerol. Growth medium consisted (per liter) of $2.0 \mathrm{~g}$ citric acid, $0.05 \mathrm{~g}$ ammonium ferric citrate, $15.0 \mathrm{~g}$ glucose, $0.5 \mathrm{~g} \mathrm{~K}_{2} \mathrm{HPO}_{4}, 0.5 \mathrm{~g} \mathrm{MgSO}_{4}, 3.5 \mathrm{~g}\left(\mathrm{NH}_{4}\right)_{2} \mathrm{HPO}_{4}, 1 \mathrm{~g}$ corn steep powder, $0.1 \mathrm{~g}$ phytosterol. The initial $\mathrm{pH}$ was adjusted to 8.0 using $2 \mathrm{~mol} \mathrm{~L}^{-1} \mathrm{NaOH}$. Media were sterilized at $115^{\circ} \mathrm{C}$ for $20 \mathrm{~min}$.

\section{Reagents}

Phytosterol (purity 95.2\%) was purchased from Davi Biochemistry Inc. (Huzhou, China), containing 47.5\% $\beta$-sitosterol, $17.7 \%$ stigmasterol, $26.4 \%$ campesterol, $3.6 \%$ brassicasterol. AD, ADD and related steroids were purchased from Sigma (St. Louis, USA). HP- $\beta$-CD was purchased from RSC Chemical Industries Co. Ltd. (Kunshan, China). Corn steep powder was purchased from Xiwang Group Co. Ltd. (Binzhou, China). Other chemicals were analytic grade reagents from Sinochem. Co. Ltd (Shanghai, China).

\section{Preparation Of Resting Cells And Biotransformation}


The seed was incubated in preculture medium at $30^{\circ} \mathrm{C}, 200 \mathrm{rpm}$ for 2 days. Then, $5 \%(\mathrm{v} / \mathrm{v})$ preculture broth was transferred to growth medium for cell expansion at $30^{\circ} \mathrm{C}, 200 \mathrm{rpm}$ for 3 days. M. neoaurum cells were harvested by centrifugation $(8000 \mathrm{~g})$ at $4^{\circ} \mathrm{C}$ for $15 \mathrm{~min}$ and the cell pellets were washed twice with $20 \mathrm{mmol} \mathrm{L}^{-1}$ phosphate buffer (PB, pH 8.0) and finally resuspended in the same buffer for further use.

All the bioconversion process with resting $M$. neoaurum cells was performed in $20 \mathrm{mmol} \mathrm{L}^{-1} \mathrm{~PB}(\mathrm{pH} 8.0)$ under non-sterile conditions in a $250-\mathrm{mL}$ flask at $30^{\circ} \mathrm{C}, 200 \mathrm{rpm}$, containing a mixture of 1:1 molar ratio of HP- $\beta-C D$ to phytosterol (approximately $4: 1$ by weight). The concentration of wet cell pellets (WCW) and phytosterol was based on the requirement of each test. The bioconversion volume $(20 \mathrm{~mL})$ was maintained constant by the addition of distilled water each day to offset the evaporation. All the bioconversion of phytosterol was performed in triplicate.

\section{Effect Of Hp- $\beta$-cd On Oxygen Availability}

Sulfite could react with the oxygen in aqueous reaction system to form sulfate. Effect of HP- $\beta$-CD on oxygen availability was determined in a reaction system containing different concentration of HP- $\beta$-CD without $M$. neoaurum cells and substrate. The reactions were performed in a 3.7-L bioreactor with $2 \mathrm{~L}$ working volume at $30{ }^{\circ} \mathrm{C}$, constant agitation and aeration rate and initiated by adding sodium sulfite (final concentration, $0.5 \mathrm{~mol} \mathrm{~L}^{-1}$ ). The oxygen utility rate was detected using exhaust gas analysis apparatus (Shandong Academy of Science, Jinan, China) when the oxygen utility rate was constant in each reaction with different concentration of HP- $\beta-C D$.

Analytical methods

The procedure of sample processing and steroids analysis by HPLC were described as reference [18]. The phytosterol was analyzed by HPLC with a Agilent Zorbax SB-C18 $(5 \mu \mathrm{m}, 4.6 \times 250 \mathrm{~mm}$, Shanghai, China) at $40{ }^{\circ} \mathrm{C}$ and a UV detector at $210 \mathrm{~nm}$. The mobile phase was composed of acetonitrile/isopropanol (70:

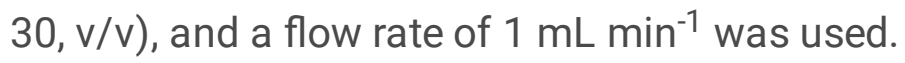

According to the instructions, the level of $\mathrm{NADH} / \mathrm{NAD}^{+}$at one-day bioconversion was detected by EnzyFluo ${ }^{\mathrm{TM}} \mathrm{NAD}^{+} / \mathrm{NADH}$ Assay Kit (EFND-100) based on an enzyme-catalyzed kinetic reaction (Beijing Lablead Biotech Co. Ltd., Beijing, China).

\section{Results}

\section{Metabolites analysis of bioprocesses with and without HP- $\beta-C D$}

In order to improve the reaction rate of sterol bioconversion, the HP- $\beta-C D$ was applied in the reaction system. But the composition of metabolites was different between the reaction system with or without 
HP- $\beta-C D$. In the reaction system without HP- $\beta-C D$, the highest production of $A D$ reached $0.4 \mathrm{~g} \mathrm{~L}^{-1}$ and the substrate consumption was not more than $20 \%$ after 3 -day bioconversion. Because of low solubility of phytosterols, the reaction rate was greatly limited. Component analysis of metabolites (Fig. 1a) indicated that the AD was the major product, which accounted for about $95 \%$ of total metabolites. Minor byproducts, such as ADD, 22-hydroxy-23,24-bisnorchol-4-en-3-one (HBC, less than 3\%), were also detected in the broth. When the bioconversion process was carried in the medium with the HP- $\beta-C D$, the conversion rate was greatly improved. The substrate was completely consumed within 2 days. However, the quantitative analysis of individual metabolites showed that much more steroid alcohols, such as HBC, 1,4-HBC, which accounted for more than $35 \%$ of total metabolites (Fig. 1b), had been produced during the biotransformation than that of the process without HP- $\beta$-CD. These metabolites were uncompleted sidechain degradation products of sterols during the bioconversion and considered as the reduced metabolites (a scheme of sterol catabolism to these metabolites was shown in Supplement Figure). Preliminarily, it was speculated that the increased production of steroid C22-alcohols was related to the higher reaction rate in a reaction system in the presence of HP- $\beta-C D$.

\section{Effect of reaction rate on the production of steroid C22-alcohols in M. neoaurum NwIB-R10}

To investigate the effect of reaction rate on the production of steroid C22-alcohols, we designed a bioprocess with $50 \mathrm{~g} / \mathrm{L}$ of substrate and different concentration of biomass. As shown in Fig. 2a, the apparent reaction rate increased with higher cells (catalysts) concentration, while the reaction rate per unit biomass (wet cell weight) decreased, which is the indication of intracellular metabolic flux (Fig. 2b). The substrate was completely consumed except for $25 \mathrm{~g} / \mathrm{L}$ biomass after 5-day conversion, and higher reaction rate per unit biomass in different reaction systems led to higher production of steroid C22alcohols (Fig. 2b). In the meantime, the impact of intracellular NADH/NAD ${ }^{+}$ratio on the formation of steroid C22-alcohols was investigated (shown in Fig. 3). The higher reaction rate per unit biomass also led to higher levels of $\mathrm{NADH} / \mathrm{NAD}^{+}$and thus to redistribution of flux toward steroid $\mathrm{C} 22$-alcohols for $\mathrm{NAD}^{+}$ regeneration putatively.

\section{Comparison of the steroid alcohols level among M. neoaurum mutants with different KshA activity}

Ksh of $M$. neoaurum belongs to a Rieske-type oxygenase which can catalyze the hydroxylation at C-9 of steroid nucleus. Mycobacterium neoaurum has two KshA homologues, KshA1 and KshA2. The kshA1 is the key gene involved in the hydroxylation at C-9 of steroid nucleus, and the $k s h A 2$ is a redundant form of $k s h A 1[6]$. The reaction of 9-hydroxylation requires two molecules of reducing equivalents (NAD(P)H) from the reductase of sterol metabolism to the oxygenase [19]. M. neoaurum mutants with different KshA activity were constructed as follows: NwIB-R10 is a kshA deletion strain, NwIB-R10-kshA is a replenishing strain $\triangle k s h A:: k s h A$, and NwIB-yV is a $K s h A$ over-expressed strain. The results of bioconversion by $M$. neoaurum mutants were shown in Table 2. There were no significant differences in reaction rate with different mutants and the substrate was consumed completely within 5-day bioconversion. No 9hydroxylated products (9-OHAD, DHBC, DHC) were detected in the sterol bioconversion with strain NwIBR10 because of kshA deletion. The 9-hydroxylated products in the sterol bioconversion with the other 
mutants increased with the increase of KshA activity of mutants. M. neoaurum NwIB-yV which is a KshA over-expressed strain even produced 9-OHAD as major product. The C-9 hydroxylation products level represented the KshA activities of mutants. Interestingly, the ratio of steroid C22/C24-alcohols (HBC, 1,4HBC, DHBC, DHC) was decreased from 51.3-22.8\% when the mutants with different 9-hydroxylation activity of was used to consume surplus NADH formed in sterol bioconversion with HP- $\beta$-CD.

Table 2

Metabolites analysis of the bioconversion with different mutants

\begin{tabular}{|c|c|c|c|c|c|c|c|c|}
\hline \multirow[t]{2}{*}{ Strains } & \multicolumn{8}{|c|}{ Ratio of steroid products (\%) ${ }^{a}$} \\
\hline & $\stackrel{9-}{\text { OHAD }}$ & $A D$ & ADD & $H B C^{b}$ & $\begin{array}{l}1,4- \\
H B C^{b}\end{array}$ & $\mathrm{DHBC}^{\mathrm{b}}$ & $\mathrm{DHC}^{\mathrm{b}}$ & $\begin{array}{l}\text { steroid } \\
\text { alcohols }\end{array}$ \\
\hline NwIB-R10 & ND & $\begin{array}{l}44.9 \pm \\
0.2\end{array}$ & $\begin{array}{l}3.8 \pm \\
0.1\end{array}$ & $\begin{array}{l}47.7 \pm \\
0.1\end{array}$ & $\begin{array}{l}3.6 \pm \\
0.3\end{array}$ & ND & ND & 51.3 \\
\hline $\begin{array}{l}\text { NwIB-R10- } \\
\text { kshA }\end{array}$ & $\begin{array}{l}26.2 \pm \\
1.1\end{array}$ & $\begin{array}{l}33.5 \pm \\
0.8\end{array}$ & $\begin{array}{l}3.3 \pm \\
0.2\end{array}$ & $\begin{array}{l}22.2 \pm \\
0.6\end{array}$ & ND & $\begin{array}{l}11.9 \pm \\
0.6\end{array}$ & $\begin{array}{l}2.9 \pm \\
0.0\end{array}$ & 37.0 \\
\hline NwIB-yV & $\begin{array}{l}75.6 \pm \\
2.3\end{array}$ & $\begin{array}{l}1.6 \pm \\
1.3\end{array}$ & ND & Trace & ND & $\begin{array}{l}18.0 \pm \\
1.2\end{array}$ & $\begin{array}{l}4.8 \pm \\
0.2\end{array}$ & 22.8 \\
\hline \multicolumn{9}{|c|}{$\begin{array}{l}\text { Note: a, The ratio of products was determined by quantitative analysis of individual metabolites using } \\
\text { area normalization after separation by HPLC. b, denotes the steroid alcohols with the hydroxyl at the } \\
\text { end of the side chain. ND, not detected. All tests were performed in a reaction system containing } 50 \mathrm{~g} \\
\mathrm{~L}^{-1} \text { substrate, } 200 \mathrm{~g} \mathrm{~L}-1 \text { HP- } \beta-C D \text { and } 50 \mathrm{~g} \mathrm{~L}^{-1} \text { biomass (wet cell weight) of different mutants in } 250- \\
\mathrm{mL} \text { flasks with } 20 \mathrm{~mL} \text { working volume for } 5 \text { days }\end{array}$} \\
\hline
\end{tabular}

The detection of NADH/NAD ${ }^{+}$level with different mutants (as shown in Fig. 4) also confirmed the effect of KshA activity on the production of steroid alcohols. As the KshA activity increase of each mutants, the intracellular NADH/NAD ${ }^{+}$level was decreased from 0.21 of strain NwIB-R10 to 0.16 of strain NwIB-yV. Obviously, the increase of $\mathrm{C}-9$ hydroxylation reaction in $M$. neoaurum accelerated the regeneration of $\mathrm{NAD}^{+}$and consequently decreased the production of steroid alcohols correspondently (Table 2).

\section{Effect of HP- $\beta-C D$ on oxygen availability}

Generally, the reduced metabolites were more inclined to be formed in the anoxic conditions [20]. Therefore, it was assumed that the presence of HP- $\beta-C D$ possibly led to oxygen shortage in the sterol bioconversion. As shown in Fig. 5 , the oxygen utility rate decreased with the increasing concentration of HP- $\beta-C D$ and was only $29 \%$ of the control when the HP- $\beta-C D$ concentration reached $25 \mathrm{~g} \mathrm{~L}^{-1}$. Using dextrin instead of HP- $\beta-C D$ to keep the same viscosity of reaction system, there was only little effect on the oxygen utility rate. Because the chemical reaction of oxygen and sodium sulfite is not a rate limiting step, it indicated that the oxygen transfer rate was decreased in the presence of HP- $\beta-C D$ due to formation of inclusion complexes. For developing an industrial bioprocess, high substrate concentration $\left(50 \mathrm{~g} \mathrm{~L}^{-1}\right.$ or more) was applied. Addition of HP- $\beta$-CD in proportion to the hydrophobic phytosterols improved the bioavailability of substrate by the formation of stable inclusion complexes. Apparently, this gave rise to 
the application of high concentration of HP- $\beta-C D\left(200 \mathrm{~g} \mathrm{~L}^{-1}\right)$ in the reaction system. The bioprocess of sterol degradation would therefore proceed under conditions of limited oxygen availability, determined by the oxygen transfer rate. Obviously, the presence of HP- $\beta-C D$ was the main factor to affect the oxygen consumption rate. The limited oxygen availability in a reaction system hampered the regeneration of $\mathrm{NADH}$ and led to redistribution of metabolic flux to the steroid alcohol in sterol conversions.

\section{Discussion}

M. neoaurum is an efficient producer of steroids by side-chain degradation of sterols under aerobic condition. Although the application of HP- $\beta$-CD-resting cells reaction system improved the sterol bioconversion by solubilizing the hydrophobic substrate, it also affected the oxygen bioavailability of reaction system and then the intracellular metabolism. It is estimated that the side-chain removal of one molecule of $\beta$-sitosterol yields 21 molecules of $\mathrm{NADH}$ and 10 molecules of $\mathrm{FADH}_{2}$ [2]. To maintain the carbon catabolism, NADH produced from the microbial metabolism must be recycled to NAD ${ }^{+}$for ATP generation via the respiratory chain. However, the regeneration activity of $N A D^{+}$and $F A D$ via respiratory chain was inhibited because of the limited oxygen bioavailability in the presence of HP- $\beta$-CD. To achieve the redox balance, the formation of the steroid alcohols is an alternative way to reoxidize NADH to NAD ${ }^{+}$ when the activity of respiratory chain is not high enough. Such a self-balance in the cofactor system of microbes can maintain functional stability and dynamic homeostasis in a redox state automatically, to adapt to the changing environment $[20,21]$. Flux redistribution is expected in organisms in which the steroid alcohols are formed to regenerate $\mathrm{NAD}^{+}$. Results also showed that a higher cellular kshA activity can accelerate NADH regeneration, and contribute to less production of steroid alcohols.

Microbial sterols side-chain degradation is initiated by C26 (or C-27) hydroxylation which is catalyzed by cytochrome P450 coupled to the consumption of oxygen and then followed by further oxidation to the sterol C26-oic acid and the cleavage of alkyl sterol side chain at C-17 via the similar fatty acid $\beta$-oxidation process [22]. Badejo et al reported a molecular adaptation to a hypoxic mode of respiration during aerobic pyrene degradation by Mycobacterium gilvum PYR-GCK [23]. With the high affinity of the aromatic ring cleavage oxygenases for molecular oxygen, the oxygenase activity is more competitive compared to the cytochrome oxidase activity. That means the reaction rate of side-chain degradation has been less affected than the regeneration of $\mathrm{NAD}^{+}$via the respiratory chain despite of the oxygen shortage in the bioprocess of sterols metabolism caused by oxygen transfer rate limitation. It will burden the regeneration of $\mathrm{NAD}^{+}$and finally lead to the formation of steroid alcohols.

The last step of side-chain degradation at $\mathrm{C}-17$ will require the participation of a hydroxyacyl-CoA lyase like other CoA-lyases, not by a conventional $\beta$-oxidation due to the presence of the cyclopentane ring $D$ [24]. In addition, the reaction rate of acyl-SCoA dehydrogenase or enoyl hydratase right near to the steroid skeleton is lower than at the terminal part of the side-chain of sterol due to the steric hindrance effect [2]. This is perhaps the reason why steroid C22-alcohols are accumulated in the process of phytosterol degradation when the intracellular metabolic flux change. 
This work demonstrated the putative mechanism of bisnorcholene derivatives accumulation in sterol bioconversion when the cyclodextrin was present to enhance the conversion rate. The redox imbalance caused by increased NADH production and oxygen shortage in the bioprocess is the main reason of the steroid alcohol's formation. The shift of metabolic flux toward steroid alcohols is the intrinsic property of redox self-balance of $M$. neoaurum metabolism. These approaches gave an insight into metabolic flux regulation to target products via biotechnological approaches reshaping the whole-cell response to redox balance and will help the rational development of industrial bioconversion strains or processing strategies.

\section{Declarations}

\section{Conflict of interest}

The authors declare that they have no conflict of interest.

\section{Ethical statement}

This article does not contain any studies with human participants or animals performed by any of the authors.

\section{Acknowledgements}

This work was supported by National Natural Science Foundation of China $(31570079,21276083)$.

\section{Author Contributions}

Xue-Dong Wang designed the experiments. Kuan Chen and Dan-Dan Cao performed experiments. XueDong Wang and Dong-Zhi Wei analyzed the experimental data and wrote the manuscript. All authors discussed the results and commented on the manuscript at all stages.

\section{References}

1. Donova, M.V., \& Egorova, O.V. (2012). Microbial steroid transformations: current state and prospects. Applied Microbiology and Biotechnology, 94(6), 1423-1447.

2. Szentirrnai, A. (1990). Microbial physiology of sidechain degradation of sterols. Journal of Industrial Microbiology \& Biotechnology, 6(2), 101-115.

3. Rodríguez-García, A., Fernández-Alegrea, E., Morales, A., Sola-Landa, A., Lorrainec, J., Macdonald邓, Dovbnya, D., Smith \M.C.M., Donova, M., \& Barreiro, C. (2016). Complete genome sequence of 'Mycobacterium neoaurum' NRRL B-3805, an androstenedione (AD) producer for industrial biotransformation of sterols. Journal of Biotechnology, 224, 64-65.

4. van der Geize, R., Yam, K., Heuser, T., Wilbrink, M.H., Hara, H., Anderton, M.C., Sim E., Dijkhuizen, L., Davies, J.E., Mohn, W.W., \& Eltis, L.D. (2007). A gene cluster encoding cholesterol catabolism in a soil 
actinomycete provides insight into Mycobacterium tuberculosis survival in macrophages. Proc Natl Acad Sci USA, 104, 1947-1952.

5. Fernandez de las Herasa, L., van der Geizeb, R., Drzyzgaa, O., Pereraa, J., \& Navarro Llorensa, J.M. (2012). Molecular characterization of three 3-ketosteroid-1-dehydrogenase isoenzymes of Rhodococcus ruber strain Chol-4. Journal of Steroid Biochemistry and Molecular Biology, 132, 271281.

6. Liu, H.H., Xu, L.Q., Yao, K., Xiong, L.B., Tao, X.Y., Liu, M., Wang, F.Q., \& Wei, D.Z. (2018). Engineered 3ketosteroid 9a-hydroxylases in Mycobacterium neoaurum: an efficient platform for production of steroid drugs 84(14), e02777-17.

7. Yeh, C.H., Kuo, Y.S., Chang, C.M., Liu, W.H., Sheu, M.L., \& Meng, M. (2014). Deletion of the gene encoding the reductase component of 3-ketosteroid 9a-hydroxylase in Rhodococcus equi USA-18 disrupts sterol catabolism, leading to the accumulation of 3-oxo-23,24-bisnorchola-1,4-dien-22-oic acid and 1,4-androstadiene-3,17-dione. Microbial Cell Factories, 13, 130.

8. Yuan, J.J., Guan, Y.X., \& Yao, S.J. (2017). Evaluation of biocompatible ionic liquids for their application in phytosterols bioconversion by Mycobacterium sp. resting cells. ACS Sustainable Chemistry \& Engineering, 5, 10702-10709.

9. Stefanov, S., Yankov, D., \& Beschkov, V. (2006). Biotransformation of phytosterols to androstenedione in two phase water-oil systems. Chemical \& Biochemical Engineering Quarterly, 20(4), 421-427.

10. Shen, Y.B., Wang, M., Li, H.N., Wang, Y.B., \& Luo, J.M. (2012). Influence of hydroxypropyl- $\beta$ cyclodextrin on phytosterol biotransformation by different strains of Mycobacterium neoaurum. Journal of Industrial Microbiology \& Biotechnology, 39, 1253-1259.

11. Donova, M.V., Nikolayeva, V.M., Dovbnya, D.V., Gulevskaya, S.A., \& Suzina, N.E. (2007). Methyl- $\beta-$ cyclodextrin alters growth, activity and cell envelope features of sterol-transforming mycobacteri Microbiology ,153,1981-1992.

12. Khomutov, S.M., Sukhodolskaya, G.V., \& Donova, M.V. (2017). The inhibitory effect of cyclodextrin on the degradation of 9a-hydroxyandrost-4-ene-3,17-dione by Mycobacterium VKM Ac-1817D. Biocatalysis \& Biotransformation, 25, 386-392.

13. Shtratnikova, V.Y., Schelkunov, M.I., Dovbnya, D.V., Bragin, E.Y., \& Donova, M.V. (2017). Effect of methyl- $\beta$-cyclodextrin on gene expression in microbial conversion of phytosterol. Applied Microbiology Biotechnology,101,4659-4667.

14. Gao, X.Q., Feng, J.X., Wang, X.D., Hua, Q., \& Wei, D.Z. (2015). Enhanced steroid metabolites production by resting cell phytosterol bioconversion. Chemical \& Biochemical Engineering Quarterly,29(4), 567-573.

15. Zhou, X.L., Zhang, Y., She, Y.B. Zhang, X., Xu, S.P., Shang, Z.H., Xia, M.L., \& Wang, M. (2019). Efficient production of androstenedione by repeated batch fermentation in waste cooking oil media through regulating NAD+/NADH ratio and strengthening cell vitality of Mycobacterium neoaurum. Bioresource Technology, 279, 209-217 
16. Wang, X.D., Chen, R., Wu, Y.Y., Wang, D., \& Wei, D.Z. (2020). Nitrate metabolism decreases the steroidal alcohol byproduct compared with ammonium in biotransformation of phytosterol to androstenedione by Mycobacterium neoaurum. Applied Biochemistry \& Biotechnology, 190, 15531560.

17. Yao, K., Xu, L.Q., Wang, F.Q., \& Wei, D.Z. (2014). Characterization and engineering of 3-ketosteroid- $\Delta 1$ dehydrogenase and 3-ketosteroid-9a-hydroxylase in Mycobacterium neoaurum ATCC 25795 to produce 9a-hydroxy-4-androstene-3,17-dione through the catabolism of sterols. Metabolic Engineering, 24, 181-191.

18. Wang, X.D., Hua, C.L., Xu, X.W., \& Wei, D.Z. (2019). Two-step bioprocess for reducing nucleus degradation in phytosterol bioconversion by Mycobacterium neoaurum NwIB-R10 $0_{\text {hsd4A. Applied }}$ Biochemistry \& Biotechnology, 188, 138-146.

19. Petrusma, M., van der Geize, R., \& Dijkhuzzzizen, L. (2014). 3-Ketosteroid 9a-hydroxylase enzymes: Rieske non-heme monooxygenases essential for bacterial steroid degradation. Antonie van Leeuwenhoek, 106, 157-172.

20. Chen, X.L., Li, S.B., \& Liu, L.M. (2014). Engineering redox balance through cofactor systems. Trends in Biotechnology, 32(6), 337-343.

21. Van Hoek, M.J., \& Merks, R.M.H. (2012). Redox balance is key to explaining full vs. partial switching to low-yield metabolism. BMC Systems Biology, 6, 22.

22. Capyk, J.K., Kalscheuer, R., Stewart, G.R., Liu, J., Kwon, H, Zhao, R., Okamoto, S., Jacobs Jr, W.R., Eltis, L.D., \& Mohn, W.W. (2009). Mycobacterial cytochrome P450 125 (Cyp125) catalyzes the terminal hydroxylation of C27-steroids. Journal of Biological Chemistry, 284(51), 35534-35542.

23. Badejo, A.C., Chung, W.H., Kim, N.S., Chai, J.C., Lee, Y.S., Jung, K.H., Kim, H.J., \& Chai, Y.G. (2014). Energy metabolism in Mycobacterium gilvum PYR-GCK: insights from transcript expression analyses following two states of induction. Plos one, 9(6), 99464.

24. García, J.L., Uhía, I., \& Galán, B. (2012). Catabolism and biotechnological applications of cholesterol degrading bacteria. Microbial Biotechnology, 5(6), 679-699.

\section{Figures}


a

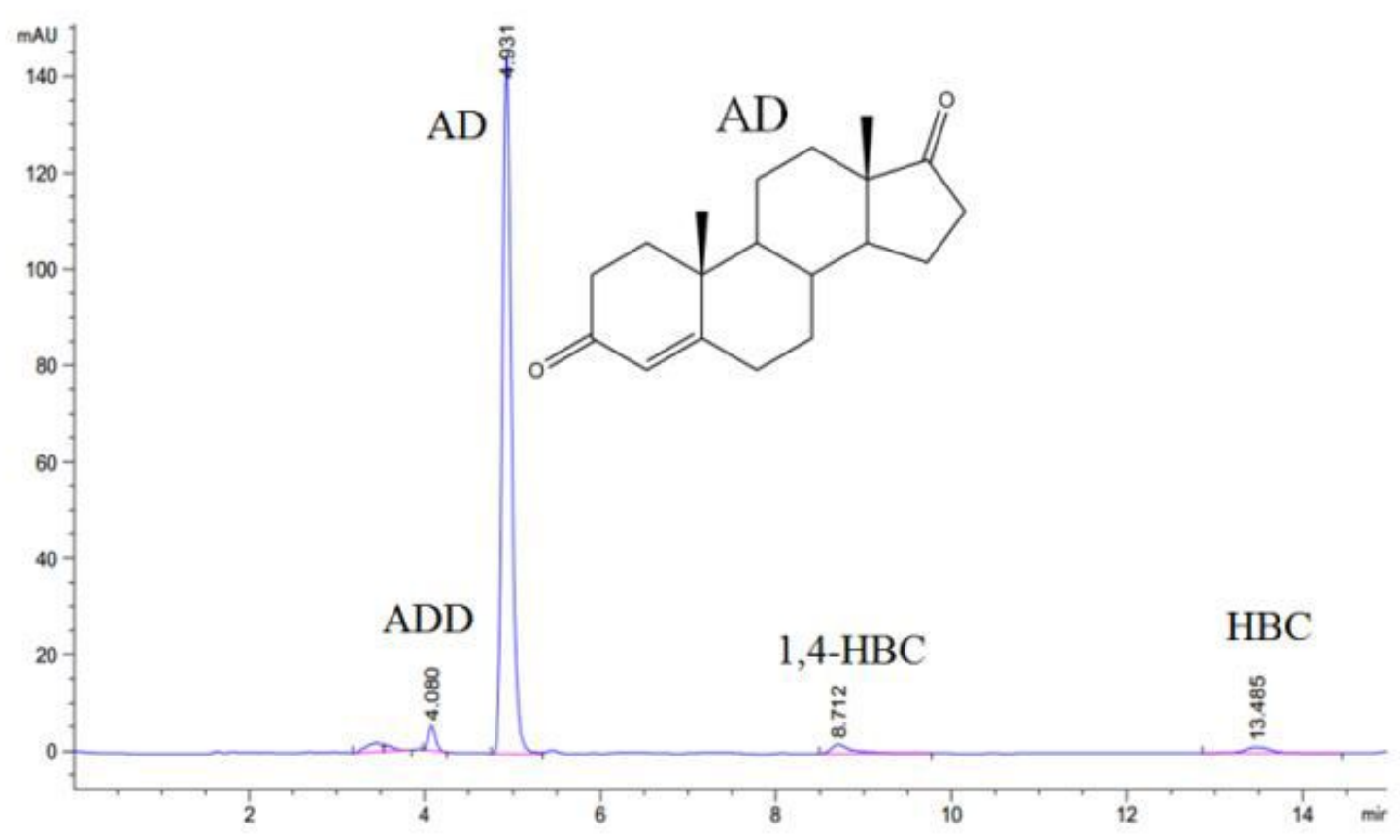

b

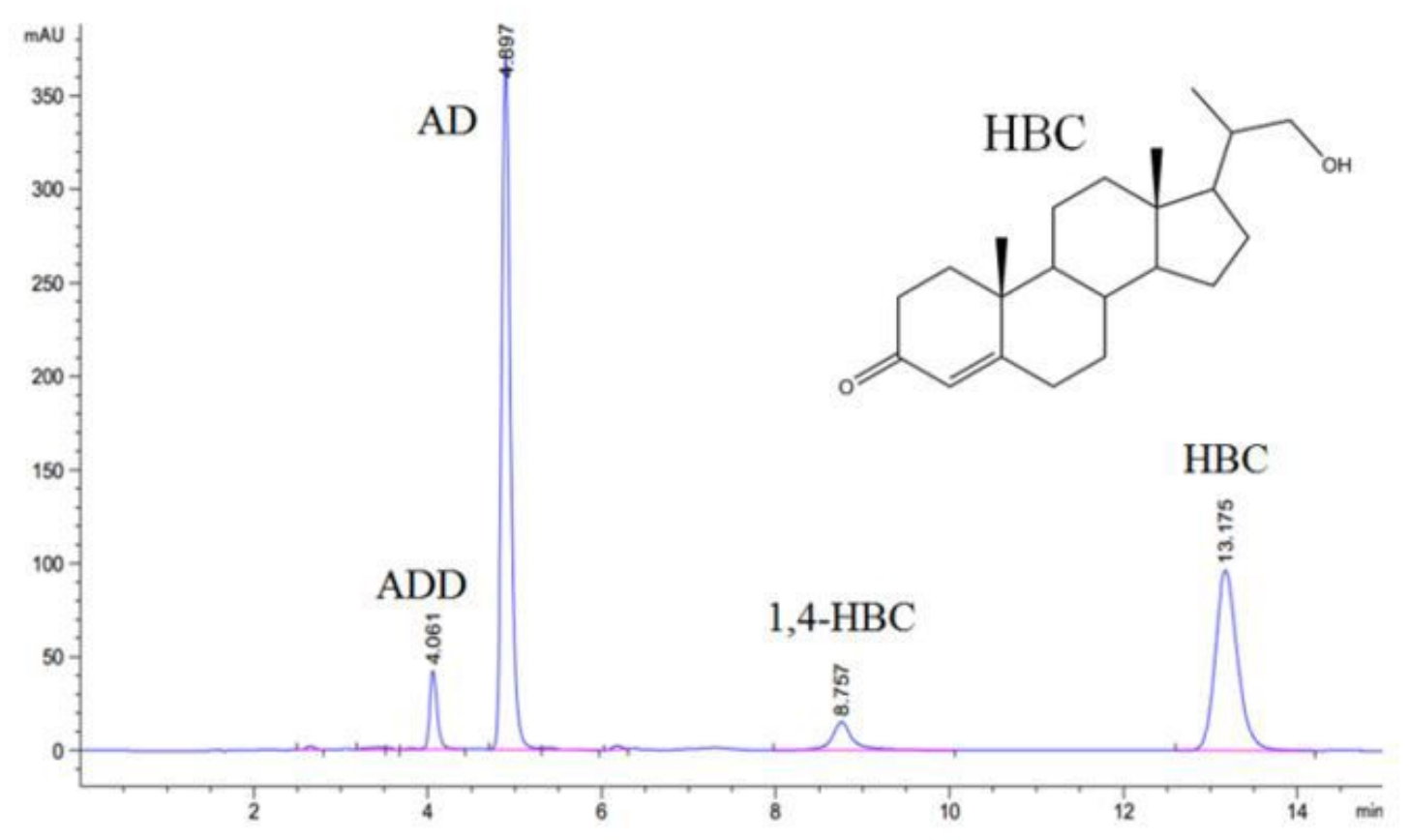

Figure 1

HPLC chromatograms of the metabolites in different reaction systems. The bioconversions in a reaction system (a) with $40 \mathrm{~g} \mathrm{~L}-1$ and (b) without HP- $\beta$-CD, containing $50 \mathrm{~g} \mathrm{~L}-1$ biomass (wet cell weight), $10 \mathrm{~g} \mathrm{~L}-1$ of phytosterol, were carried out with M. neoaurum NwIB-R10 resting cell in 250-mL flasks with $20 \mathrm{~mL}$ of reaction volume for 3 days 


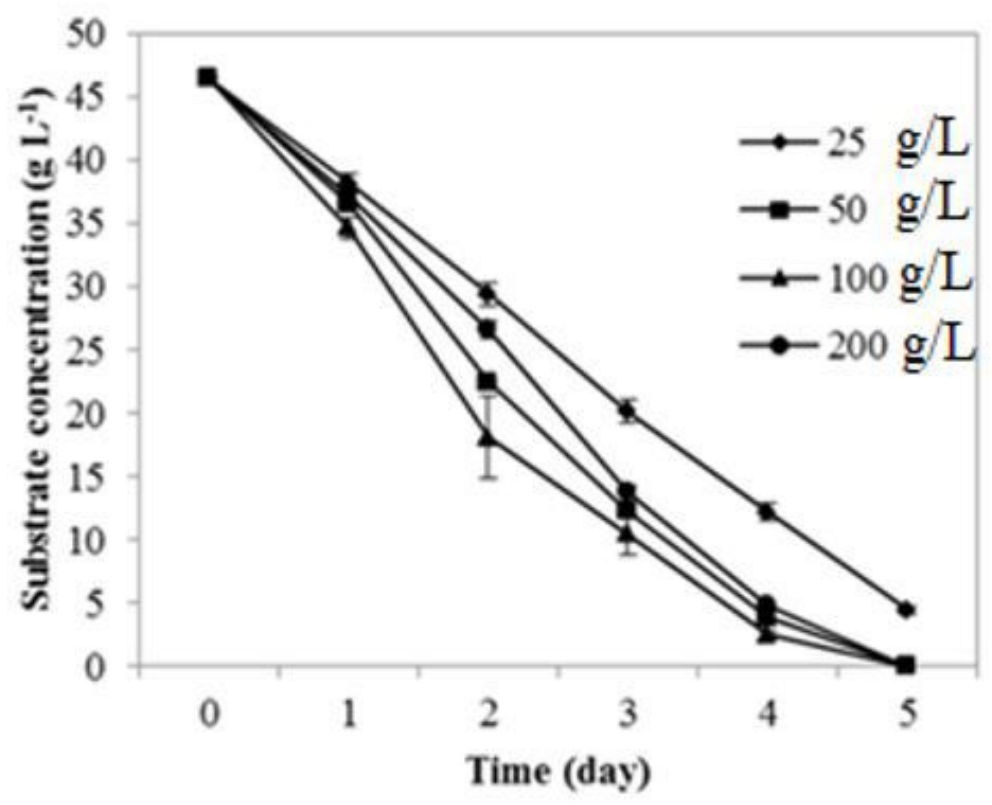

b

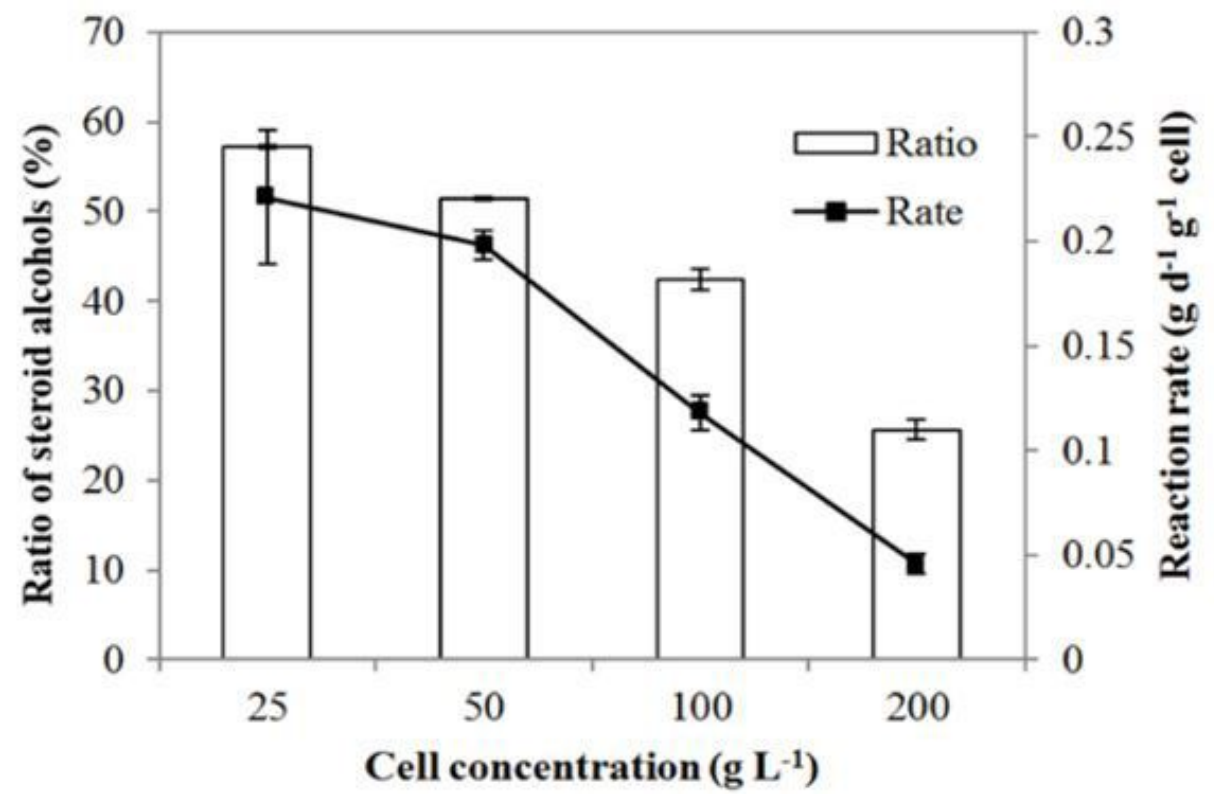

Figure 2

Effect of the reaction rate on the production of steroid alcohols. a, substrate profile; $b$, reaction rate per unit biomass (wet cell weight) and ratio of the steroid alcohols. All tests were performed in a reaction system containing $50 \mathrm{~g} \mathrm{~L}-1$ substrate, $200 \mathrm{~g} \mathrm{~L}-1 \mathrm{HP}-\beta-\mathrm{CD}$ and 25-200 g L-1 biomass (wet cell weight) in $250-\mathrm{mL}$ flasks with $20 \mathrm{~mL}$ working volume for 5 days. The substrate consumption over $24 \mathrm{~h}$ was 
assumed as the initial reaction rate. The ratio of steroid alcohols was determined by the quantitative analysis of individual metabolites using area normalization after separation by HPLC

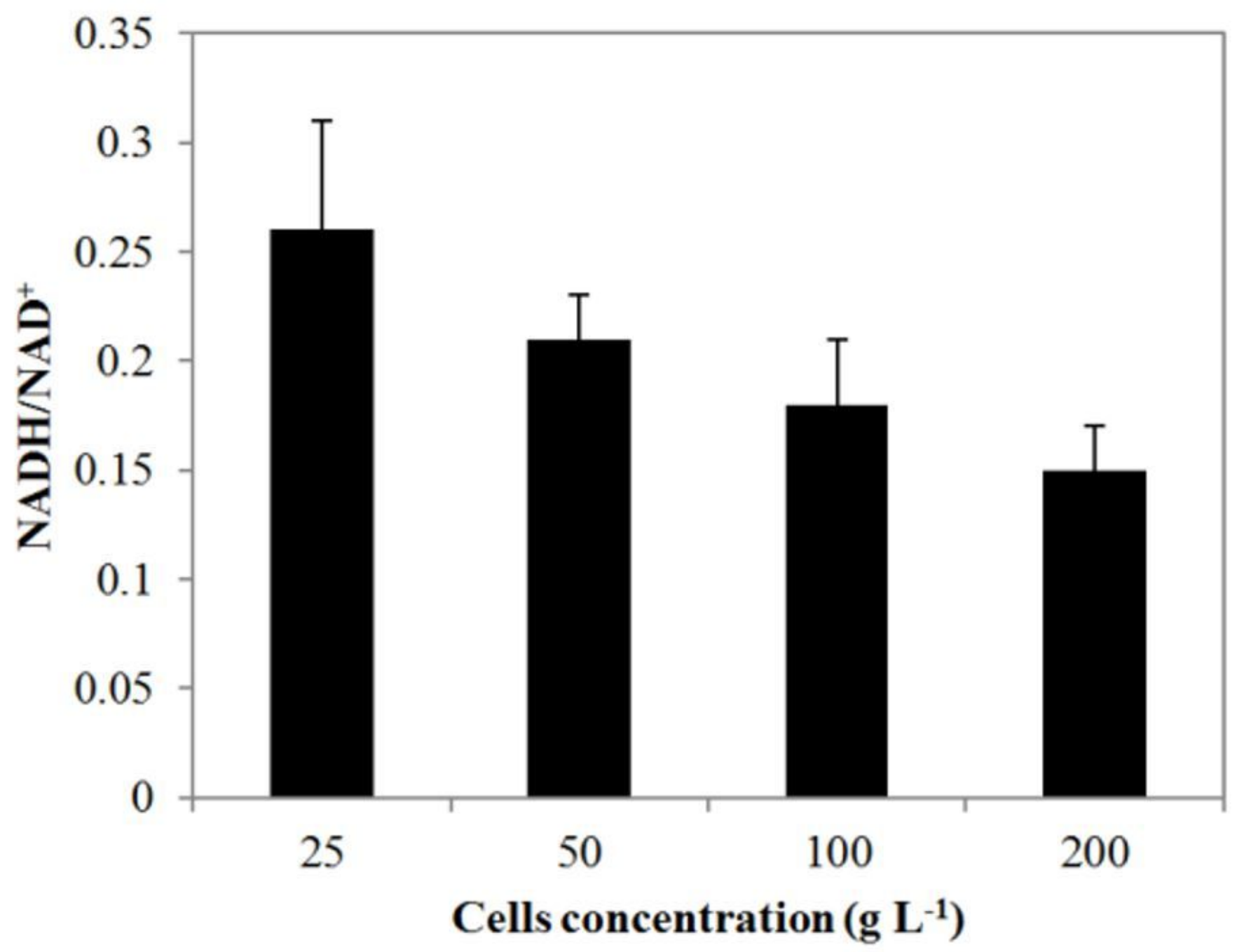

Figure 3

$\mathrm{NADH} / \mathrm{NAD}+$ level in a reaction system with different cell concentration. There was a significant difference between groups $(p<0.01)$. Intracellular NADH/NAD+ level was determined at 1-day bioconversion 


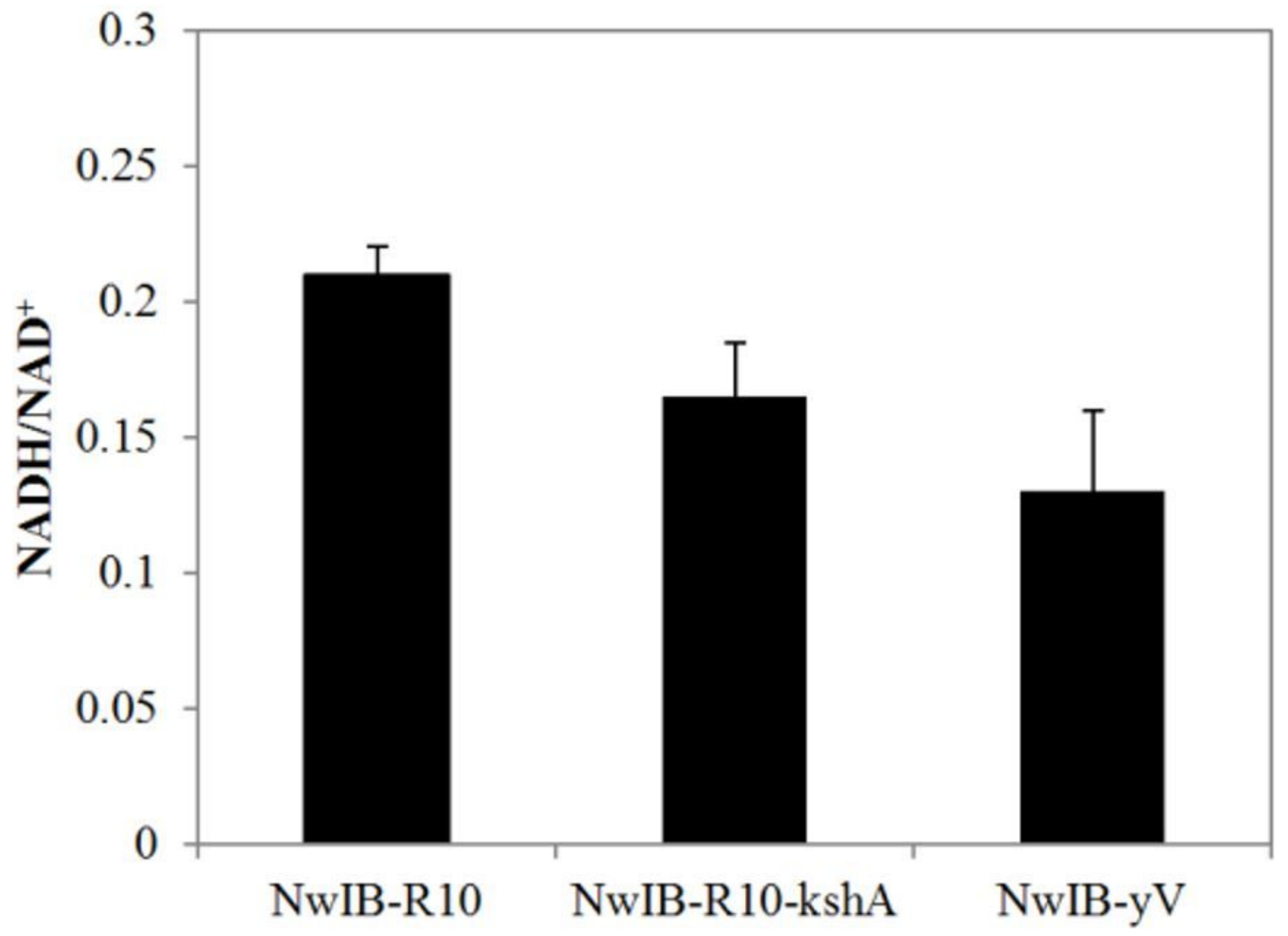

Figure 4

$\mathrm{NADH} / \mathrm{NAD}+$ level in a reaction system with different mutants. There was a significant difference between groups $(p<0.01)$. All bioconversion was performed in a reaction system containing $50 \mathrm{~g} \mathrm{~L}-1$ substrate, $200 \mathrm{~g} \mathrm{~L}-1$ HP- $\beta-C D$ and $50 \mathrm{~g} \mathrm{L-1}$ biomass (wet cell weight) of different mutants in 250-mL flasks with $20 \mathrm{~mL}$ working volume for 5 days. Intracellular NADH/NAD+ level was determined at 1 day bioconversion 


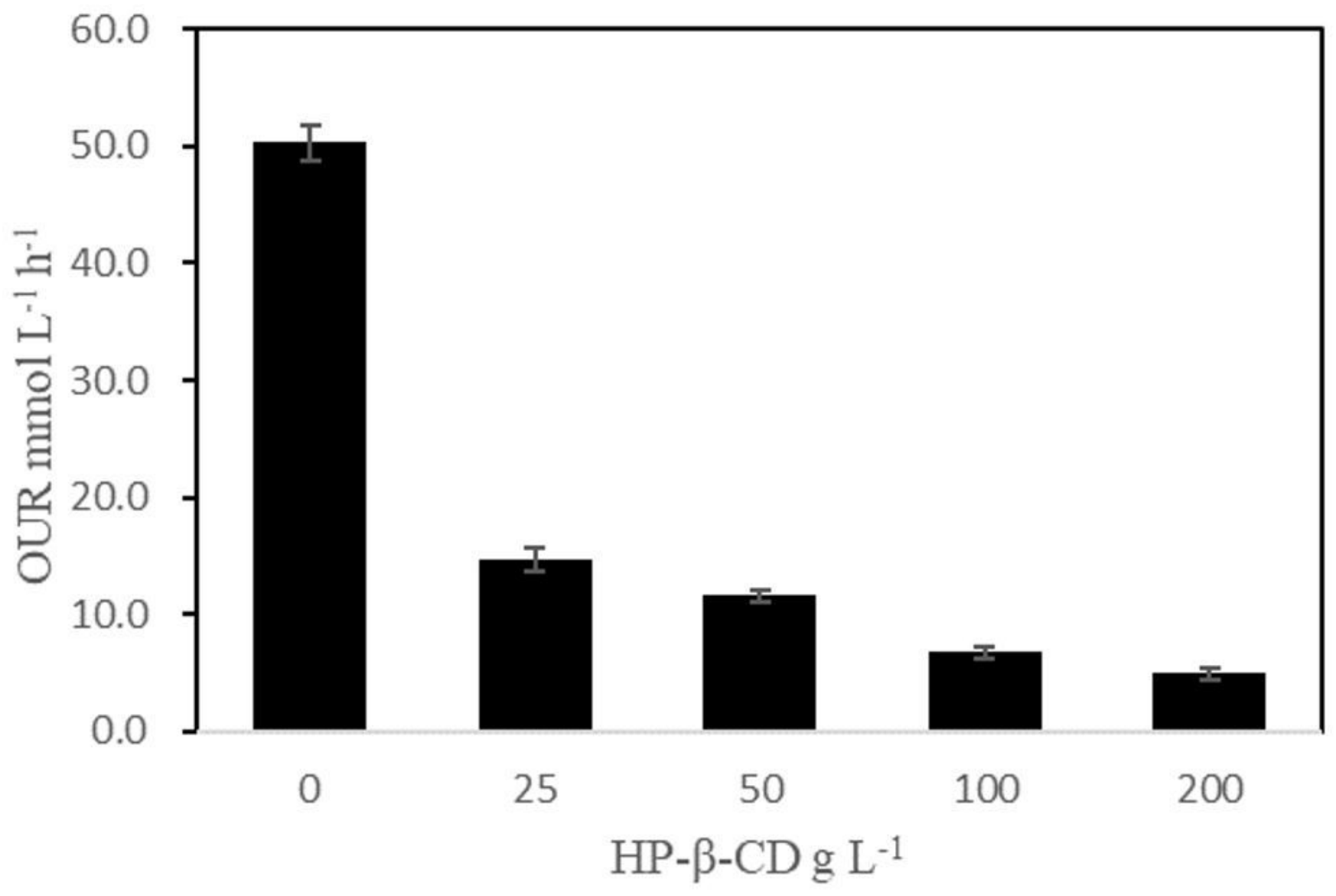

Figure 5

Effect of HP- $\beta-C D$ on oxygen utility rate

\section{Supplementary Files}

This is a list of supplementary files associated with this preprint. Click to download.

- SupplementFigure.docx 